\title{
STUDY OF KNOWLEDGE, ATTITUDE AND PRACTICES OF MOTHERS TOWARDS BREASTFEEDING IN A CENTRAL INDIAN HOSPITAL
}

\author{
Sachin Wankhede1, Sarika Thakare2 ${ }^{2}$ Nivedita Goverdhan ${ }^{3}$
}

${ }^{1}$ Associate Professor, Department of Obstetrics and Gynaecology, Indira Gandhi Government Medical College, Nagpur. ${ }^{2}$ Assistant Professor, Department of Obstetrics and Gynaecology, Indira Gandhi Government Medical College, Nagpur. ${ }^{3}$ Senior Resident, Department of Obstetrics and Gynaecology, Indira Gandhi Government Medical College, Nagpur.

\section{ABSTRACT}

\section{BACKGROUND}

The aim of this study was to assess Knowledge, Attitude and Practice towards breastfeeding among mothers.

\section{MATERIALS AND METHODS}

This was a descriptive study conducted over a period of 2 years in maternity ward in a central Indian hospital. A total of 2000 mothers were interviewed. The data was collected using a predesigned questionnaire. All data collected was analysed.

\section{RESULTS}

75.21\% booked and 67.93\% unbooked cases had awareness of benefits of breastfeeding. More than 95\% of mothers irrespective of educational status had knowledge of early initiation of breastfeeding but only $71.25 \%$ actually initiated breastfeeding within 1 hour. Colostrum was given by approximately $95 \%$ mothers and $14.75 \%$ gave prelacteal feeds. $96.3 \%$ mothers exclusively breastfed their babies till 4 months of age. Knowledge about weaning was fair. On demand breastfeeding was practised by $71.59 \%$ mothers. $68.35 \%$ opined that breastfeeding should be stopped during any maternal illness. $36.65 \%$ were aware of contraceptive benefit of lactation. $73.75 \%$ mothers had knowledge of requirement of extra calories during lactation while $80.15 \%$ said that burping should be done after each feed.

\section{CONCLUSION}

Though mothers had good knowledge of breastfeeding, the gap between knowledge and practice needs to be addressed. Health professionals, more so doctors have a vital role to play in educating nursing mothers.

\section{KEYWORDS}

Breastfeeding, Knowledge, Attitude, Practice.

HOW TO CITE THIS ARTICLE: Wankhede S, Thakare S, Goverdhan N. Study of knowledge, attitude and practices of mothers towards breastfeeding in a Central Indian hospital. J. Evolution Med. Dent. Sci. 2017;6(15):1171-1174, DOI: $10.14260 /$ Jemds/2017/255

\section{BACKGROUND \\ The superiority of breast milk as the best food for infant is well documented. ${ }^{1}$ Breastfeeding has distinctive species- specific advantages leading to better survival and optimum growth potential in infants, especially those receiving exclusive breastfeeding in the first six months of life. \\ Poor breastfeeding practices and their consequences are one of the world's major problems and it is a man-made problem. The practise of breastfeeding has shown a declining trend in the course of last 40 years; and it is only in the last decade or so that an arrest in decline and in some places an improving trend is being noted. ${ }^{2}$ However, in developing countries like India, which have been traditional bastions of breastfeeding, a somewhat ominous trend to decreased initiation and decreased duration along with increased bottle feeding has been noted, particularly in urban areas.}

Financial or Other, Competing Interest: None.

Submission 12-01-2017, Peer Review 04-02-2017,

Acceptance 11-02-2017, Published 20-02-2017.

Corresponding Author:

Dr. Sachin Wankhede,

Department of Obstetrics and Gynaecology,

Indira Gandhi Government Medical College,

Nagpur.

E-mail: drsachinwankhede@yahoo.co.in

DOI: $10.14260 /$ jemds $/ 2017 / 255$

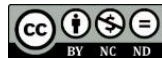

Among the various reasons cited, lack of positive support and advice regarding breastfeeding by health care personnel needs utmost attention. In the past decade and half, this need of joining hands and re-instating breastfeeding has been felt by most people and attention has been drawn from all over the world. National and international agencies have been active in promoting breastfeeding at various forums and conferences.

The World Health Assembly in 1992 adopted the declaration that during the first four to six months of life no food or liquid other than breast milk is required to meet the normal infant requirement. ${ }^{3}$

Although there is an extensive literature on knowledge, practices and attitude of breastfeeding from various parts of the world, 4 there is paucity of literature available regarding the same from this part of the country. This study is aimed at recognising the knowledge, practices and attitude of breastfeeding in this part of the country, the problem encountered so as to overcome it with a hope that this will be an early step in the Baby Friendly Hospital Initiative.

\section{MATERIALS AND METHODS}

This is a descriptive study carried out in the Department of Obstetrics and Gynaecology at a central Indian hospital over a period of 2 years. This is a study of knowledge, practice and attitude of breastfeeding in mothers. 2000 mothers entered the study. Careful history was taken as per the predesigned 
proforma and mothers were interviewed in maternity ward regarding knowledge, attitude and practice of breastfeeding within 24 hours of delivery. Interviewing was done by a single person using pretested, semi-structured, open and closed ended questionnaire after obtaining informed consent.

The findings were recorded as per the predesigned proforma and all data collected was tabulated and analysed.

\section{RESULTS}

\begin{tabular}{|c|c|c|}
\hline Characteristics & Number & Percentage \\
\hline \multicolumn{3}{|c|}{ Maternal Age (Years) } \\
\hline$<20$ & 55 & $2.75 \%$ \\
\hline $20-24$ & 1120 & $56 \%$ \\
\hline $25-29$ & 538 & $26.9 \%$ \\
\hline$>29$ & 287 & $14.35 \%$ \\
\hline \multicolumn{3}{|c|}{ Religion } \\
\hline Hindu & 1229 & $61.45 \%$ \\
\hline Muslim & 349 & $17.45 \%$ \\
\hline Others & 422 & $21.1 \%$ \\
\hline \multicolumn{3}{|c|}{ Maternal Education } \\
\hline Primary school & 361 & $18.05 \%$ \\
\hline Middle school & 561 & $28.05 \%$ \\
\hline High school & 304 & $15.2 \%$ \\
\hline Higher secondary & 155 & $7.75 \%$ \\
\hline Graduate & 18 & $0.9 \%$ \\
\hline Illiterate & 601 & $30.05 \%$ \\
\hline \multicolumn{3}{|c|}{ Number of Children } \\
\hline One & 1002 & $50.1 \%$ \\
\hline More than one & 998 & $49.9 \%$ \\
\hline \multicolumn{3}{|c|}{ Socioeconomic Strata } \\
\hline Higher & 0 & $0 \%$ \\
\hline Middle & 134 & $6.7 \%$ \\
\hline Lower & 1866 & $93.3 \%$ \\
\hline $\begin{array}{r}\text { Table 1. Distribut } \\
\text { to Socioden }\end{array}$ & $\begin{array}{l}\text { Study Su } \\
\text { ohic Char }\end{array}$ & $\begin{array}{l}\text { According } \\
\text { stics }\end{array}$ \\
\hline
\end{tabular}

Out of 2000 study subjects, majority were between 20-24 years, belonged to Hindu religion (61.45\%), 69.95\% were literates and $30.05 \%$ were illiterates. The distribution of primiparas and multiparas was almost similar. Majority $(93.3 \%)$ belonged to lower socioeconomic strata.

\begin{tabular}{|c|c|c|}
\hline $\begin{array}{c}\text { Serial } \\
\text { No. }\end{array}$ & Factor & $\begin{array}{c}\text { Percentage } \\
\text { of Correct } \\
\text { Responses }\end{array}$ \\
\hline 1 & Knows benefits of breastfeeding \\
\hline & a) To baby & $100 \%$ \\
\hline & b) To mother & $58 \%$ \\
\hline 2 & Time of initiation of breastfeeding & $71.25 \%$ \\
\hline 3 & Prelacteal feeds & $85.25 \%$ \\
\hline 4 & Colostrum feeding & $95.8 \%$ \\
\hline 5 & Duration of exclusive breastfeeding & $96.3 \%$ \\
\hline 6 & Ideal position of breastfeeding & $95 \%$ \\
\hline 7 & Demand feeding & $71.59 \%$ \\
\hline 8 & Role of diet in breast milk secretion & $96.65 \%$ \\
\hline 9 & Knowledge on expressed breast milk & $54 \%$ \\
\hline 10 & Storage of expressed milk & $6 \%$ \\
\hline 11 & Breastfeeding during maternal & $31.65 \%$ \\
\hline 12 & Contraceptive benefit of lactation & $36.65 \%$ \\
\hline 13 & Requirement of extra calories during & $73.75 \%$ \\
\hline 14 & Knowledge of burping after feed & $80.15 \%$ \\
\hline Table 2. Knowledge of Mothers about Breastfeeding \\
\hline \multicolumn{2}{|c|}{}
\end{tabular}

While $71.25 \%$ had the knowledge to initiate breastfeeding within 1 hour of delivery, only 51\% actually did so. Only $4.2 \%$ felt that colostrum was bad for the baby and $14.75 \%$ gave prelacteal feeds. A satisfactory $96.3 \%$ gave correct response to exclusive breastfeeding but most of them for 4 months. Honey was the most common prelacteal feed given. Majority $(64.9 \%)$ were of the opinion that weaning should be started between 4-6 months. Knowledge regarding expressed breast milk and its storage was very poor. Majority (80.15\%) said that burping should be done after every feed.

\begin{tabular}{|c|c|c|}
\hline Characteristics & Number & Percentage \\
\hline \multicolumn{3}{|c|}{ Maternal Age (Years) } \\
\hline $20-24$ & 32 & $58.18 \%$ \\
\hline $25-29$ & 807 & $72.05 \%$ \\
\hline$>29$ & 374 & $69.52 \%$ \\
\hline \multicolumn{3}{|c|}{ Maternal Education } \\
\hline Primary school & 228 & $63.25 \%$ \\
\hline Middle school & 409 & $72.91 \%$ \\
\hline High school & 240 & $78.95 \%$ \\
\hline Higher secondary & 104 & $67.10 \%$ \\
\hline Graduate & 16 & $88.89 \%$ \\
\hline Illiterate & 428 & $71.22 \%$ \\
\hline \multicolumn{3}{|c|}{ Number of Children } \\
\hline One & 700 & $69.86 \%$ \\
\hline More than one & 725 & $72.65 \%$ \\
Breastfeeding Initiation within One Hour \\
\hline \multicolumn{3}{|c|}{ Maternal Characteristics with regard to } \\
\hline
\end{tabular}

Mothers more than 20 years of age initiated breastfeeding earlier as compared to mothers less than 20 years of age. Irrespective of the education status majority initiated breastfeeding within one hour. Mothers who were educated up to graduation $(88.89 \%)$ had the highest percentage. Maternal parity had no influence on breastfeeding initiation.

\section{DISCUSSION}

The major physiological event of the puerperium is the establishment of lactation. Though breast milk is the ideal inimitable milk and nutrition for baby, many mothers in developed countries still reject breastfeeding in favour of artificial feeding. Researchers have shown the importance of short-term as well as long-term benefits of breastfeeding, like protection against GIT infection and respiratory infection. In our circumstances, illiteracy, low socioeconomic strata and poor health of women prevail. Though breastfeeding is done traditionally, correct methods and counselling regarding the advantages of breastfeeding need to be explained.

Breastfeeding improves childhood cognitive functions. The presence of long chain fatty acids in breast milk, particularly docosahexaenoic acid, are important more so in low birth weight babies for neurological development. Breastfeeding is also shown to lower the incidence of atopic illnesses like asthma and eczema in babies, more so important when family history of illness is present. Breastfeeding is also shown to have other possible benefits like reduced incidence of juvenile onset diabetes mellitus, inflammatory bowel disease and neoplastic disease in childhood. Small overall protective effect also helps in preventing breast cancer. It also gives natural relative contraceptive effect. 
As breastfeeding has many advantages, it is important that mothers are given accurate information and encouraged to breastfeed successfully whenever possible. Conversely, mothers who choose to bottle feed should be given proper instructions on breastfeeding practice and need to be supported in their decision making.

In the UK, about $55 \%$ of mothers initially breastfeed their babies but many discontinue after a short time. Factors associated with higher prevalence of breastfeeding are upper social class, primiparity and older age of mother. We found an overall incidence of $96.21 \%$ of breastfeeding in our study and majority of the mothers were young primi of 20-24 years of age i.e. $56 \%$. Literates as well as illiterates have adopted the practice of breastfeeding. The differences noted in illiterate mothers are faulty position of breastfeeding, late colostrum feeding and higher incidence of prelacteal feed administration.

Approximately, 93.3\% mothers belonged to lower socioeconomic strata. However, R.K. Gurudeva et al ${ }^{5}$ reported that $54.2 \%$ mothers belonged to lower socioeconomic strata. Routinely, non-affordability of infant feeding formulae and improper counselling regarding proper age of weaning contributes for longer duration of breastfeeding. Rohini Sehgal et $\mathrm{al}^{6}$ in their study of breastfeeding and weaning practices reported that $81.5 \%$ women started early breastfeeding, rejection of colostrum by $7 \%$, exclusive breastfeeding in $48 \%$ and total duration of breastfeeding being 15-53 months. Prelacteal feeds were given by $52 \%$ mothers. Breastfeeding was considered healthy by $75.05 \%$ and a contraceptive by $28 \%$ of mothers. She concluded for a need to include patient education programed on breastfeeding parameters during antenatal care.

In our study, ANC counselling regarding ten steps of breastfeeding was done in majority $(75.21 \%)$ of booked patients and $67.93 \%$ of unbooked mothers. However, Chaturvedi P. et al ${ }^{7}$ reported that $54.5 \%$ booked mothers and $30.03 \%$ unbooked mothers were informed regarding benefits of breastfeeding.

With the existing knowledge regarding breastfeeding, $28.35 \%, 37.65 \%$ and $34 \%$ cases decided to breastfeed before pregnancy, during pregnancy and after birth respectively. Calvo B. et $\mathrm{al}^{8}$ reported that $60 \%$ of the sample took the decision to breastfeed before pregnancy, 21\% during pregnancy and 6\% after birth. Difference noted may be because of literacy rate and antenatal advice.

Early initiation of breastfeeding within one hour was slightly more in educated group than illiterates. Similar trends were seen by G. Subbulakshmi et al ${ }^{9}$ Contrary evidence to this also exists as was seen by Bhavani Belavady et $\mathrm{al}^{10}$. The breastfeeding initiation time was less in older mothers than in teenagers. Reasons may be lack of knowledge and privacy in ward.

In our study parity has no effect on initiation of breastfeeding. B.N. Ghosh ${ }^{11}$ and R.D. Bansal et al ${ }^{12}$ were of the opinion that maternal age and parity has no effect on breastfeeding initiation. However, they stressed the importance of proper counselling and support to younger mothers for starting breastfeeding earlier.

R. M. Akuse ${ }^{13}$ states most health care workers, routinely gave prelacteal feeds in $70.6 \%$, under special circumstances in $24.5 \%$ and those who didn't advocate were $4.9 \%$. Reasons for prelacteal feeds administration included perceived breast milk insufficiency (33.1\%), medical reasons (32.5\%) and nonmedical reasons (34.4\%). Prelacteal feed most commonly used by our patients was honey (77.63\%). Reasons for prelacteal feeds administration noted were similar like breast milk insufficiency (35.93\%), medical reasons $(1.02 \%)$ and non-medical reasons (63.56\%).

Demand feeding was practised by majority (71.59\%). In majority $(64.9 \%)$ time of weaning was 4-6 months. Because of proper counselling, the sensitised women in booked cases wanted to continue breastfeeding up to 1.5 to 2 years. Unbooked mothers, due to lack of proper knowledge continued breastfeeding till next birth or the baby spontaneously discontinued. However, R.K. Gurudeva et al ${ }^{5}$ reported that $35.4 \%$ breast fed their babies at one year of age. Gayatri Ray et al ${ }^{14}$ reported that $41.7 \%$ of mothers breast fed their babies even after the age of 18 months and $28.3 \%$ of mothers stopped breastfeeding before the first birthday.

After assessing maternal knowledge regarding breastfeeding during maternal illness $68.35 \%$ opined that breastfeeding should be stopped during any illness, $14.35 \%$ had no idea and only $6.25 \%$ were of the opinion of no need to discontinue breastfeeding. Umesh Kapil et $\mathrm{al}^{15}$ in their study found percentages of respondents who were of the opinion to discontinue breastfeeding if mother is suffering from breast cancer (48\%), TB (57\%), Malaria (67\%), and Diarrhoea $(84 \%)$. The percentages of girls wrongly believing that breastfeeding should be discontinued if mother was suffering from TB, Malaria and Diarrhoea were 96, 85 and 81 respectively Kapil U. et al. ${ }^{16}$

G Subbulakshmi et $\mathrm{al}^{9}$ in her study on colostrum, found statistically significant differences in feeding practices in both urban and rural areas. The factors like poverty, rural area, lack of services avoided colostrum feeding and better income group, general awareness of mothers, joint family system and hospital delivery were having positive influences on colostrum feeding. Religion did not affect the practice of breastfeeding. The reason for not feeding colostrum noted were elder's negative attitude towards colostrum feeding, dai's denial, bad for child health, caesarean delivery and absence of colostrum secretion.

Gayatri Ray ${ }^{14}$ after her study of feeding and weaning practices in urban and slum community reported that colostrum was not fed in those cases as it was not considered milk and was thought harmful for baby. Neither maternal literacy nor economic status significantly influenced the pattern of introduction of breast milk. Inadequacy of breast milk or failure has prompted $72.3 \%$ of mothers to introduce top milk, while $66.3 \%$ did so for better growth or for creating a habit.

For the average, healthy, full-term infant there are no disadvantages to breastfeeding provided that the mother's milk supply is ample and that her diet contains sufficient amount of protein and vitamin. Infrequently, allergens to which the infant is sensitised may be conveyed in the milk. In such cases, an attempt should be made to find its presence rarely is a valid reason for weaning the baby. Medical contraindications to breastfeeding include infection with HIV, primary CMV and Hepatitis B virus (Beherman R. E al). ${ }^{17}$

Though breastfeeding is done traditionally in our region by all our lactating mothers, it is the need of the hour to educate the mothers as well as to update the knowledge of 
Medial and Paramedical Workers, Dais and Anganwadi Workers in providing knowledge in antenatal visits in spite of busy schedule.

\section{CONCLUSION}

Though breastfeeding is done traditionally, there is a need for providing counselling information regarding colostrum feeding, age of initiation, weaning, correct position and duration of breastfeeding. Routine antenatal breast examination and preparation of mothers for breastfeeding during pregnancy and delivery helps to avoid future feeding difficulties. Special counselling is required in mothers with HIV infection, active TB, malaria and Hepatitis B.

There is a need for updating knowledge and practical skills in medical and paramedical personnel to promote and support optimum breastfeeding. To become baby friendly, health care facilities must practise each of the 10 steps to successful breastfeeding developed by WHO and UNICEF.

Eventually, it is imperative for us, the medical professionals concerned with providing the children of today with a better and healthier tomorrow, to convince the society after having convinced ourselves.

\section{REFERENCES}

[1] Ahmed F, Clemens JD, Rao MR, et al. Community based evaluation of the effect of breast feeding on the risk of microbiologically confirmed or clinically presumptive shigellosis in Bangladeshi children. Pediatrics 1992;90(3):406-11.

[2] Martinez GA, Dodd DA, Samartgedes JA. Milk feeding patterns in the United States during the first twelve months of life. Pediatrics 1981;68(6):863-8.

[3] Gopalan S, Puri RK. Breast feeding and infant growth. Indian Pediatrics 1992;29(8):1079-86.

[4] Notzon F. Trends in infant feeding in developing countries. Pediatrics 1984;74(4 Pt 2):648-66.

[5] Gurudeva RK, Gargye AK, Singh SB, et al. Infant feeding patterns in Rewa. Indian J Pediat 1982;49(6):815-8.
[6] Sehgal R, Agrawal S, Banerjee K, et al. Breast feeding and weaning practices- a hospital based study. Obs \& Gynae Today 2006;11(4):240-3.

[7] Chaturvedi P, Banait N. Knowledge and attitude regarding breast feeding, in mothers attending antenatal clinics. Indian J Pediatr 2000;67(4):259-62.

[8] Calvo B, Millan C, Alvarez JD, et al. Maternal attitude to breast feeding and difficulties in the immediate puerperium. Aten Primaria 1992;10(3):650-4.

[9] Subbulakshmi G, Udipi SA, Nirmalamma N. Feeding of colostrum in urban and rural areas. Indian J Pediatr 1990;57(2):191-6.

[10] Belavady B, Pasricha S, Shankar K. Studies on lactation and dietary habits of the Nilgiri hill tribes. Ind Jour Med Res 1959;47(2):221-33.

[11] Ghosh BN. Feeding habits of infants and children in South India (on 600 families). Ind Jour Med Res 1966;54(9):889-97.

[12] Bansal RD, Ghosh BN, Bharadwaj UD. et al. Infant feeding and weaning practices in Simla-Hills, Himachal Pradesh. Indian J Med Res 1973;61:1869-75.

[13] Akuse RM, Obinya EA. Why healthcare workers give prelacteal feeds? European Journal of Clinical Nutrition 2002;56(8):729-34.

[14] Ray G, Reddy DC. Some aspects of feeding and weaning practices in an urban slum community. Indian Journal of Public Health 1988;32(4):207-8.

[15] Kapil U, Paul D, Manocha S. Knowledge and attitude among child development project officers towards breast feeding. Indian J Paediatr 1989;56(6):771-4.

[16] Kapil U, Manocha S. Knowledge and attitude towards breast feeding among adolescent girls. Indian J Paediatr 1990;57(3):401-4.

[17] Behrman RE, Kleigman RM, Arvin AM, et al. In: Nelson WE, Vaughan Ill VC. eds. Nelson book of Pediatrics. $15^{\text {th }}$ edn. Philadelphia: WB Saunders Company 1996. 